\title{
Pengujian Kualitas Kompos di Kebun Raya Cibodas terhadap Pertumbuhan Sawi Hijau (Brassica rapa)
}

\author{
Compost Quality Testing at Cibodas Botanical Gardens on The Growth \\ of Green Mustard (Brassica $\underline{\text { rapa }})$
}

Fitri Kurniawati M. I. L.

Diterima 16 Agustus 2017/Disetujui 07 Februari 2018

\begin{abstract}
The experiment to find out the best quality of compost made by using two merck of decomposer (Katalek and Promi) as a medium for planting green mustard (Brassica rapa var. parachinensis L.), has been conducted from February to March 2015 at Compost Unit of Cibodas Botanical Gardens LIPI. The purpose of this experiment was to obtain a good quality of compost for plant growth. The experimental design used was randomized block design $(R A K)$ with four replications. The treatment used consisted of 3 combinations of compost using Katalek decomposer and soil media, 3 compost combinations using Promi decomposer and soil media and one control (soil only). Variables measured consist of height, leaf number, root length, and fresh weight of green mustard. Data were analyzed by univariate analysis of variance (ANOVA) at $\alpha=0.05$ level when significant it was followed by Duncan test. The results showed that compost with Katalek decomposer was the best quality compost compared to compost with Promi decomposer. Planting media which was a combination of compost and soil, whether using a Katalek or Promi decomposer could support growth of green mustard greens, especially at the level of 2:1. The best medium for green mustard was shown by the 2-part compost medium with the Katalek decomposer and 1 part of soil.
\end{abstract}

Keyword: compost decomposer, high growth, leaf number, root length and wet weight

\begin{abstract}
ABSTRAK
Percobaan untuk mengetahui kualitas kompos terbaik yang dibuat dengan menggunakan dua jenis merek perombak kompos (Katalek dan Promi) sebagai media tanam tanaman sawi (Brasica rapa), telah dilaksanakan pada bulan Februari sampai Maret 2015 di Unit Pengolahan Kompos Balai Konservasi Tumbuhan Kebun Raya Cibodas Lembaga Ilmu Pengetahuan Indonesia (LIPI). Tujuan pengujian ini ialah untuk memperoleh produk kompos sampah organik yang berkualitas baik untuk pertumbuhan tanaman. Rancangan percobaan yang digunakan ialah rancangan acak kelompok (RAK) dengan empat ulangan. Perlakuan yang digunakan terdiri atas 3 kombinasi kompos yang menggunakan perombak Promi dan media tanah, 3 kombinasi kompos yang menggunakan perombak Katalek dan media tanah serta satu kontrol (media tanah saja). Variabel yang diamati ialah tinggi, jumlah daun, panjang akar dan bobot sawi hijau. Data dianalisis dengan sidik ragam (ANOVA) pada taraf $\alpha=0.05$. Jika efek perlakuan nyata, selanjutnya diuji dengan uji Duncan. Hasil menunjukkan bahwa kompos dengan perombak Katalek merupakan kompos dengan kualitas terbaik dibandingkan kompos dengan perombak Promi. Media tanam yang merupakan kombinasi kompos dan tanah, baik yang menggunakan perombak Katalek ataupun Promi merupakan media tanam yang dapat menunjang pertumbuhan sawi hijau terutama pada taraf 2:1. Media terbaik untuk pertumbuhan sawi hijau ditunjukkan oleh media 2 bagian kompos dengan perombak Katalek dan 1 bagian tanah.
\end{abstract}

Kata kunci: jumlah daun, panjang akar dan bobot basah, perombak pengomposan, pertumbuhan tinggi.

Balai Konservasi Tumbuhan Kebun Raya Cibodas-LIPI

Jl. Kebun Raya Cibodas, Cipanas, Cianjur PO BOX 19 Sindanglaya-Cianjur Jawa Barat-Indonesia. Telepon: 0263 - 512233, 520448, Fax: 0263 - 512233 Email: fitr015@lipi.go.id / upiet_v3@yahoo.com (*Penulis korespondensi) 


\section{PENDAHULUAN}

Pengelolaan sampah (limbah padat) merupakan masalah klasik yang kerap terjadi di setiap daerah, begitu pun di kawasan Konservasi ex-situ Balai Konservasi Tumbuhan Kebun Raya Cibodas (KRC) - LIPI. Aktifitas pembersihan kebun seperti penyapuan potongan rumput, serasah daun, serta pengumpulan sampah bawaan pengunjung telah menghasilkan banyak sampah. Volume sampah yang dihasilkan KRC setiap hari hampir mancapai 700-900 Kg, baik sampah organik maupun anorganik. Hal ini perlu untuk ditangani secara baik agar tidak menimbulkan masalah di kawasan KRC. Pengelolaan sampah tidak cukup hanya dilakukan dengan manajemen 3P (Pengumpulan, Pengangkutan dan Penimbunan di TPA) (Suprapto, 2010), namun juga upaya untuk mereduksi sampah sebelum ke TPA, seperti pengomposan atau melalui program $3 \mathrm{R}$ (reduce, reuse, recycle).

Pengomposan merupakan upaya yang sudah ada sejak lama digunakan untuk mereduksi sampah organik (Caceres et al., 2015). KRC telah memiliki unit yang menangani pengolahan kompos sebagai upaya pemanfaatan sampah organik dalam mereduksi timbunan sampah di TPA KRC. Potensi pemanfaatan sampah organik di KRC sangat besar dimana sumber sampah organik dapat dihasilkan setiap harinya. Sampah organik yang dimanfaatkan menjadi kompos berguna untuk meningkatkan kualitas kesuburan tanah. Manfaat kompos dalam mendukung pertumbuhan dan hasil tanaman telah dilaporkan oleh banyak peneliti, kompos berperan dalam memperbaiki sifat fisika, kimia, maupun biologi tanah (Sastro et al., 2012).

Kompos yang diproduksi KRC diberi label Biopuralink (Gambar 1) yang dimanfaatkan untuk kegiatan internal KRC sebagai bahan pupuk organik pada kegiatan pemeliharaan tanaman dan sebagai media tanam tanaman koleksi. Secara eksternal pemanfaatan kompos Biopuralink juga biasa digunakan pada kegiatan penghijauan dan untuk dijual pada masyarakat umum. Kompos Biopuraling diproduksi KRC sebanyak 19.29 ton pada periode tahun kerja 2013 (KRC, 2013) dan 27.35 ton pada tahun 2014 (KRC, 2014). Saat ini Unit Kompos KRC sedang melakukan upaya pengembangan produksi dan peningkatan kualitas kompos.

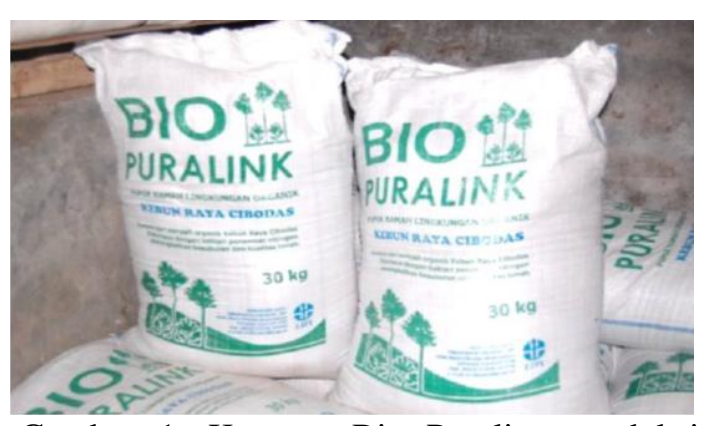

Gambar 1. Kompos Bio Puraling produksi Kebun Raya Cibodas-LIPI.

Peningkatan produksi dilakukan dengan meningkatkan jumlah produksi kompos yang dilakukan dengan mengoptimalkan pemanfaatan sampah organik yang berasal dari kebun. Upaya peningkatan kualitas kompos yang di produksi KRC dilakukan melalui pengujian dengan membandingkan penggunaan jenis merek perombak kompos yang berbeda. Perombak kompos dapat mempengaruhi proses dan kualitas kompos (Isroi, 2008). Hal ini tergantung pada komposisi dan jenis mikroorganisme yang dikandung oleh masingmasing perombak. Selama ini Unit Kompos KRC menggunakan jenis perombak merek Katalek dan sebagai pembanding dalam pengujian digunakan perombak merek Promi yang memiliki harga jual lebih ekonomis dan teknik pengomposannya tidak memerlukan pembalikan sesuai dengan petunjuk penggunaan di kemasannya. Manfaat lebih dari merek Promi seperti harga yang ekonomis dan efisien dalam penyerapan penggunaan tenaga kerja pada proses pengomposan menjadi pertimbangan yang utama sehingga jenis perombak merek Promi dipilih sebagai pembanding pengujian kualitas kompos ini.

Percobaan ini juga memanfaatkan tanaman sawi hijau (Brassica rapa var. parachinensis L.) sebagai indikator. Pemilihan jenis sawi sebagai tanaman indikator karena kompos KRC belum pernah diuji kualitasnya terhadap pertumbuhan tanaman hortikultura. Pengujian kompos KRC pada tahun 2013 baru diujikan pada pembibitan Damar Mata Kucing (Shorea javanica) (Kurniawati dan Miranti, 2013). Sawi hijau merupakan sayuran yang responsif terhadap kondisi hara dalam tanah, gejala kekurangan atau kelebihan hara akan mudah dikenali dari visualisasi pertumbuhannya. Selain itu sawi hijau juga banyak dibudidayakan di kawasan Cipanas Cianjur. Pemanfaatan kompos yang diproduksi KRC 
pada tanaman hortikultura akan memberikan gambaran positif terhadap petani hortikultura di sekitar KRC, sehingga dapat menambah informasi bahwa kompos KRC dapat dimanfaatkan di lahan pertanian hortikultura.

\section{BAHAN DAN METODE}

Bahan yang digunakan dalam percobaan ini adalah perombak kompos merek Katalek dan Promi, sampah organik (rumput dan serasah dari kebun koleksi), media tanah dengan kandungan hara seperti disajikan pada Tabel 1, serta sawi hijau (Brassica rapa var. parachinensis L.) sebagai tanaman indikator. Percobaan dilakukan di Unit Kompos KRC pada bulan Februari sampai April 2015.

Percobaan dirancang dengan menggunakan rancangan acak kelompok (RAK) dengan menguji 7 perlakuan kompos terhadap tanaman sawi yang diulang sebanyak 4 kali. Perlakuan terdiri atas $\mathrm{A}=$ media tanah saja (kontrol), $\mathrm{B}=$ 2 bagian kompos katalek +1 bagian tanah, $\mathrm{C}=$ 1 bagian kompos katalek +1 bagian tanah, $\mathrm{D}=$ 1 bagian katalek +2 bagian tanah, $\mathrm{E}=2$ bagian kompos Promi +1 bagian tanah, $\mathrm{F}=1$ bagian kompos Promi +1 bagian tanah dan $\mathrm{G}=1$ bagian kompos Promi dan 2 bagian tanah. Percobaan dilakukan dengan menggunakan polibag kapasitas $5 \mathrm{Kg}$. Pengamatan dilakukan terhadap variabel pertumbuhan sawi hijau yaitu: pengukuran tinggi tanaman, jumlah daun, penghitungan panjang akar serta bobot sawi pada saat panen.

Data dianalisis dengan sidik ragam (ANOVA) pada taraf $\alpha=0.05$ untuk mengetahui apakah perlakuan memberikan efek bermakna terhadap variabel respons yang diamati. Apabila efek perlakuan tersebut bermakna, maka dilanjutkan dengan uji Duncan (Gomez dan Gomez, 1995).

Tabel 1. Hasil analisis unsur hara pada tanah di Kawasan Kebun Raya Cibodas

\begin{tabular}{|c|c|c|c|}
\hline No. & Kriteria & Nilai & Status \\
\hline 1 & $\mathrm{pH}$ & 5.1 & masam \\
\hline 2 & $\mathrm{~N}$ total $(\%)$ & 0.23 & sedang \\
\hline 3 & $\mathrm{P}_{2} \mathrm{O}_{5}(\mathrm{ppm})$ & 9.5 & sangat rendah \\
\hline 4 & $\mathrm{~K}_{2} \mathrm{O}(\%)$ & 12.0 & rendah \\
\hline
\end{tabular}

\section{HASIL DAN PEMBAHASAN}

\section{Pertumbuhan Tinggi Tanaman Sawi Hijau}

Pengamatan pertumbuhan tinggi tanaman sawi hijau selama 5 MST ditunjukkan pada Gambar 2. Hasil menujukkan bahwa perlakuan media kompos memberikan hasil pertumbuhan tinggi tanaman yang berbeda dengan kontrol. Sawi memiliki daya tumbuh yang responsif terhadap kandungan hara sehingga pada minggu ketiga setelah tanam perbedaan tinggi tanaman sawi hijau sudah berbeda, sedangkan pada minggu kedua secara umum pertumbuhan sawi hijau masih serempak. Hal ini diduga karena hingga 2 MST kandungan hara untuk sawi hijau pada semua media tanam masih mencukupi kebutuhan tanaman, dan berubah pada 3 MST terutama pada kontrol yang mulai mengalami defisiensi hara.

Hasil analisis ragam terhadap pertambahan tinggi tanaman sawi hijau selama 5 MST disajikan pada Tabel 2. Hasil menunjukkan bahwa perlakuan media berpengaruh nyata saat 2 MST dan sangat nyata saat 5 MST terhadap pertambahan tinggi tanaman. Hasil uji terhadap perbedaan antar perlakuan pada 5 MST menunjukkan bahwa tanaman dengan perlakuan 2 bagian media kompos dengan perombak Katalek dan 1 bagian tanah memberikan hasil tinggi tanaman yang tertinggi yaitu $30.6 \mathrm{~cm}$ dan terendah pada kontrol yaitu $4.38 \mathrm{~cm}$ meskipun tidak berbeda nyata dengan perlakuan media kompos dengan perombak Katalek lainnya dan juga pada perlakuan 2 bagian kompos dengan perombak Promi dan 1 bagian tanah. Hal ini menunjukkan bahwa kandungan hara pada media kontrol tidak dapat mencukupi kebutuhan pertumbuhan tanaman sawi hijau hingga 5 MST.

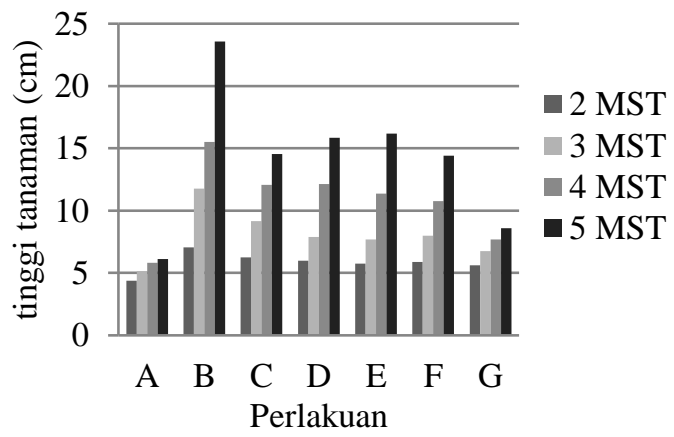

Gambar 2. Pertumbuhan tinggi tanaman sawi hijau pada setiap minggu pengamatan hingga 5 MST. 


\section{Jumlah Daun Sawi Hijau}

Perlakuan dengan menggunakan media kompos menunjukkan hasil yang sangat nyata terhadap jumlah daun tanaman sawi pada 5 MST dan tidak berpengaruh nyata pada 2 MST (Tabel 3). Perbedaan antar perlakuan pada 5 MST menunjukkan perbedaan yang nyata terhadap jumlah daun terutama jika dibandingkan dengan kontrol. Perlakuan media yang menggunakan kompos dengan perombak Katalek dan Promi secara umum menunjukkan hasil yang berbeda tidak nyata pada masingmasing taraf perbandingan media yang sama. Perlakuan media dengan penambahan kompos menyediakan ketersediaan unsur hara yang lebih baik untuk mencukupi kebutuhan pertumbuhan sawi hijau. Hal ini juga sejalan dengan hasil penelitian Hapsoh et al. (2017) yang menyatakan bahwa Aplikasi kompos mempengaruhi terhadap pertumbuhan tanaman hortikuktura, pada penelitiannya kompos berpengaruh terhadap tinggi tanaman pertambahan tinggi, umur berbunga dan umur panen Cabai. Jumlah daun terbanyak ditunjukkan oleh perlakuan 2 bagian kompos dengan perombak Katalek dan 1 bagian tanah yaitu dengan nilai rata-rata sebanyak 12 helai daun, meskipun secara statisik tidak berbeda nyata dengan perlakuan media dengan perombak katalek lainnya, serta dengan perlakuan 2 bagian kompos dengan Perombak Promi dan 1 bagian tanah .

\section{Panjang Akar Sawi Hijau}

Perlakuan media kompos menunjukkan hasil yang sangat nyata terhadap panjang akar tanaman sawi hijau pada 5 MST (Tabel 4). Perbedaan perlakuan media kompos dan kontrol pada 5 MST menunjukkan perbedaan yang nyata terhadap panjang akar. Perlakuan antar media kompos pada taraf perbandingan yang sama menunjukkan hasil yang tidak berbeda nyata pada perbandingan 2:1 dan berbeda tidak nyata pada taraf lain yang sama. Perlakuan terbaik yang memberikan panjang akar terpanjang adalah pada media dengan 2 bagian perombak Promi dan 1 bagian tanah yaitu sebesar $23 \mathrm{~cm}$.

Tabel 2. Pertumbuhan tinggi tanaman sawi hijau (Brassica rapa var. parachinensis L.) pada 1 dan 5 MST

\begin{tabular}{clccc}
\hline Kode & \multicolumn{2}{c}{ Perlakuan } & 2 MST $(\mathrm{cm})$ & 5 MST $(\mathrm{cm})$ \\
\hline A & Kontrol (tanah) & & $4.38 \mathrm{a}$ & $5.30 \mathrm{a}$ \\
$\mathrm{B}$ & 2 Kompos Katalek & $: 1$ Tanah & $7.05 \mathrm{c}$ & $30.60 \mathrm{c}$ \\
$\mathrm{C}$ & 1 Kompos Katalek & $: 1$ Tanah & $6.25 \mathrm{bc}$ & $21.38 \mathrm{bc}$ \\
$\mathrm{D}$ & 1 Kompos Katalek & $: 2$ Tanah & $6.00 \mathrm{bc}$ & $22.68 \mathrm{bc}$ \\
$\mathrm{E}$ & 2 Kompos Promi & $: 1$ Tanah & $5.75 \mathrm{bc}$ & $25.25 \mathrm{bc}$ \\
$\mathrm{F}$ & 1 Kompos Promi & $: 1$ Tanah & $5.88 \mathrm{bc}$ & $20.88 \mathrm{~b}$ \\
$\mathrm{G}$ & 1 Kompos Promi & $: 2$ Tanah & $5.63 \mathrm{~b}$ & $11.55 \mathrm{a}$ \\
\hline & F hitung & $3.64 *$ & $8.64 * *$ \\
& Koefisien variasi & & $14.00 \%$ & $30.00 \%$ \\
\hline
\end{tabular}

Keterangan: angka yang diikuti huruf yang berbeda pada kolom yang sama adalah berbeda nyata menurut uji lanjut duncan pada taraf 5\%. *) menunjukkan bahwa nilai analisis varian bernilai signifikan pada $\alpha=0.05 . * *$ ) menunjukkan nilai analisis sangat signifikan pada $\alpha=0.05$

Tabel 3. Jumlah daun tanaman sawi hijau (Brassica rapa var. parachinensis L.) pada 2 dan 5 MST

\begin{tabular}{clccc}
\hline Kode & \multicolumn{2}{c}{ Perlakuan } & 2 MST (helai) & 5 MST (helai) \\
\hline A & Kontrol (Tanah) & : 1 Tanah & $3.5 \mathrm{a}$ & $4.3 \mathrm{a}$ \\
$\mathrm{B}$ & 2 Kompos Katalek & $: 1$ Tanah & $4.0 \mathrm{bc}$ & $12.5 \mathrm{c}$ \\
$\mathrm{C}$ & 1 Kompos Katalek & $4.0 \mathrm{bc}$ & $9.8 \mathrm{bc}$ \\
$\mathrm{D}$ & 1 Kompos Katalek & $: 2$ Tanah & $4.0 \mathrm{bc}$ & $10.8 \mathrm{bc}$ \\
$\mathrm{E}$ & 2 Kompos Promi & $: 1$ Tanah & $3.8 \mathrm{ab}$ & $11.8 \mathrm{bc}$ \\
$\mathrm{F}$ & 1 Kompos Promi & $: 1$ Tanah & $4.3 \mathrm{c}$ & $9.3 \mathrm{~b}$ \\
$\mathrm{G}$ & 1 Kompos Promi & $: 2$ Tanah & $4.0 \mathrm{bc}$ & $6.5 \mathrm{a}$ \\
\hline & F hitung & 2.30 & $6.94 * *$ \\
& Koefisien variasi & $4.00 \%$ & $8.00 \%$ \\
\hline
\end{tabular}

Keterangan: angka yang diikuti huruf yang berbeda pada kolom yang sama adalah berbeda nyata menurut uji lanjut duncan pada taraf $5 \%{ }^{*}$ ) menunjukkan bahwa nilai analisis varian bernilai signifikan pada $\alpha=0.05 . * *$ ) menunjukkan nilai analisis sangat signifikan pada $\alpha=0.05$. 
Tersedia online di http://journal.ipb.ac.id/index.php/jhi

Tabel 4. Panjang akar sawi hijau (Brassica rapa var. parachinensis L.) 5 MST.

\begin{tabular}{clcc}
\hline Kode & \multicolumn{2}{c}{ Perlakuan } & $2 \mathrm{MST}(\mathrm{cm})$ \\
\hline A & Kontrol (Tanah) & $: 1$ Tanah & $6.75 \mathrm{a}$ \\
B & 2 Kompos Katalek & $: 1$ Tanah & $20.00 \mathrm{c}$ \\
C & 1 Kompos Katalek & $: 2$ Tanah & $13.75 \mathrm{~b}$ \\
D & 1 Kompos Katalek & $: 1$ Tanah & $12.25 \mathrm{~b}$ \\
E & 2 Kompos Promi & $: 1$ Tanah & $23.00 \mathrm{c}$ \\
F & 1 Kompos Promi & $: 2$ Tanah & $11.50 \mathrm{ab}$ \\
G & 1 Kompos Promi & & $9.00 \mathrm{ab}$ \\
\hline & F hitung & & 13.11 \\
& Koefisien variasi & & $423 \%$ \\
\hline
\end{tabular}

Keterangan: angka yang diikuti huruf yang berbeda pada kolom yang sama adalah berbeda nyata menurut uji lanjut duncan pada taraf $5 \%$. $*$ ) menunjukan bahwa nilai analisis varian bernilai signifikan pada $\alpha=0.05 . * *$ ) menunjukkan nilai analisis sangat signifikan pada $\alpha=0.05$.

\section{Bobot Sawi Hijau}

Perlakuan media kompos menunjukkan pengaruh yang sangat nyata terhadap bobot sawi hijau pada 5 MST (Tabel 5). Perbedaan perlakuan media kompos menunjukkan perbedaan yang sangat nyata antara kontrol dan perlakuan lainnya terhadap bobot sawi hijau, kecuali pada perlakuan 1 bagian media kompos dengan perombak Promi dan 2 bagian tanah yang tidak berbeda nyata dan berbeda tidak nyata pada 1 bagian media kompos dengan perombak Promi dan 1 bagian tanah. Pada taraf perbandingan media kompos yang sama menunjukkan hasil yang berbeda nyata pada taraf 2:1 dan 1:2, sedangkan pada taraf $1: 1$ berbeda tidak nyata. Perlakuan terbaik yang memberikan bobot sawi terbesar ditunjukkan oleh media dengan 2 bagian kompos dengan perombak Katalek dan 1 bagian tanah. Hasil pemaparan data pengamatan di atas secara umum menunjukkan bahwa perlakuan media kompos berpengaruh nyata pada pertumbuhan sawi hijau baik pada pertumbuhan tinggi, jumlah daun, panjang akar dan bobot sawi hijau. Media kontrol menunjukkan hasil pertumbuhan sawi hijau terendah. Media kompos memperbaiki kondisi nutrisi dan fisik media tanam, sehingga sawi hijau dapat tumbuh lebih baik dari pada pertumbuhan sawi pada perlakuan kontrol. Derajat keasaman tanah atau pH tanah di Kawasan Kebun Raya Cibodas termasuk pada kondisi agak masam yaitu sebesar 5.1 (Tabel 5). Pada kondisi derajat keasaman dibawah netral unsur hara tanah umumnya berada pada kondisi kurang tersedia bagi tanaman. Haryanto et al. (2007) menyatakan bahwa tanah yang cocok untuk ditanami sawi adalah tanah gembur, banyak mengandung humus, subur, serta pembuangan airnya baik. Derajat kemasaman $(\mathrm{pH})$ tanah yang optimum untuk pertumbuhannya adalah antara pH 6 sampai pH 7. Kompos bermanfaat sebagai media tanam ataupun pupuk organik yang dapat digunakan untuk memperbaiki kondisi fisik dan kimia media.

Tabel 5. Bobot tanaman sawi hijau (g) saat panen (5 MST).

\begin{tabular}{clcc}
\hline Kode & \multicolumn{2}{c}{ Perlakuan } & $5 \mathrm{MST}$ \\
\hline $\mathrm{A}$ & Kontrol (Tanah) & $: 1$ Tanah & $17.60 \mathrm{a}$ \\
$\mathrm{B}$ & 2 Kompos Katalek & $: 1$ Tanah & $90.68 \mathrm{c}$ \\
$\mathrm{C}$ & 1 Kompos Katalek & $: 2$ Tanah & $36.25 \mathrm{~b}$ \\
$\mathrm{D}$ & 1 Kompos Katalek & $: 1$ Tanah & $36.86 \mathrm{~b}$ \\
$\mathrm{E}$ & 2 Kompos Promi & $: 1$ Tanah & $41.51 \mathrm{~b}$ \\
$\mathrm{~F}$ & 1 Kompos Promi & $: 2$ Tanah & $19.78 \mathrm{ab}$ \\
$\mathrm{G}$ & 1 Kompos Promi & & $8.33 \mathrm{a}$ \\
\hline & F hitung & & $11.86 * *$ \\
& Koefisien variasi & & $51 \%$ \\
\hline
\end{tabular}

Keterangan: angka yang diikuti huruf yang berbeda pada kolom yang sama adalah berbeda nyata menurut uji lanjut duncan pada taraf $5 \%$. ${ }^{*}$ ) menunjukkan bahwa nilai analisis varian bernilai signifikan pada $\alpha=0.05 . * *$ ) menunjukkan nilai analisis sangat signifikan pada $\alpha=0.05$. 
Tabel 6. Kandungan mikroorganisme dalam kompos dengan Perobak Katalek dan Promi

\begin{tabular}{|c|c|c|c|}
\hline \multirow{2}{*}{ No. } & \multirow{2}{*}{ Mikroorganisme } & \multicolumn{2}{|c|}{ Populasi (CFU) } \\
\hline & & Kompos Katalek & Kompos Promi \\
\hline 1 & Bakteri & $2.5 \times 10^{9}$ & $2.25 \times 10^{9}$ \\
\hline 2 & Jamur & $7.6 \times 10^{4}$ & $8.3 \times 10^{4}$ \\
\hline 3 & Pelarut Fospat & $1.7 \times 10^{7}$ & $3.4 \times 10^{7}$ \\
\hline 4 & Pemfiksasi Nitrogen & $4.4 \times 10^{7}$ & $1.8 \times 10^{7}$ \\
\hline
\end{tabular}

Media kompos juga mengandung banyak mikroorganisme menguntungkan yang dapat memperbaiki kondisi hara pada media tanam. Perombak kompos mengandung mikroorganisme yang berperan dalam dekomposisi bahan mentah kompos dan menghasilkan asam humat yang berperan dalam menyediakan unsur hara yang tidak tersedia menjadi tersedia bagi tanaman. Hal ini sejalan dengan pendapat Novizan (2005) yang menyatakan bahwa manfaat pupuk organik kompos adalah menyediakan unsur hara makro dan mikro, mengandung asam humat (humus) yang mampu meningkatkan kapasitas tukar kation tanah, meningkatkan aktivitas mikroorganisme tanah, pada tanah masam penambahan bahan organik dapat membantu meningkatkan $\mathrm{pH}$ tanah. Oleh karena itu, pertumbuhan sawi pada media kompos menunjukkan hasil yang lebih baik daripada pada kontrol (tanah).

Kandungan mikroorganisme pada kompos dengan perombak Katalek dan Promi disajikan pada Tabel 6. Secara umum dapat dilihat bahwa kompos dengan perombak Katalek mengandung total bakteri dan bakteri pemfiksasi Nitrogen yang lebih banyak dibanding kompos dengan perombak Promi yaitu masing-masing sebesar $2.5 \times 10^{9} \mathrm{CFU}$ dan $4.4 \times 10^{7}$ CFU. Kompos Promi mengandung populasi jamur dan populasi bakteri pelarut fospat yang lebih banyak yaitu masing-masing sebesar $8.3 \times 10^{4} \quad \mathrm{CFU}$ dan $3.4 \times 10^{7}$ CFU. Perbedaan kandungan mikroorganisme pada media tanam tersebutlah yang diduga memiliki peranan tidak langsung dalam mempengaruhi perbedaan hasil pertumbuhan sawi hijau pada penelitian ini.

Unsur nitrogen di udara merupakan bentuk $\mathrm{N}$ tidak tersedia bagi tanaman, sehingga harus difiksasi/ ditambat oleh mikroorganisme tanah dan diubah bentuknya menjadi tersedia bagi tanaman. Mikroorganisme penambat $\mathrm{N}$ ada yang bersimbiosis dengan tanaman dan ada pula yang hidup bebas di sekitar perakaran tanaman. Mikroorganisme penambat $\mathrm{N}$ simbiotik antara lain: Rhizobium sp. Mikroorganisme penambat $\mathrm{N}$ nonsimbiotik misalnya: Azospirillum sp dan Azotobacter sp. Bakteri pemfiksasi non simbiotik seperti Azotobacter sp dapat memproduksi hormon pertumbuhan yang dapat merangsang tanaman tumbuh dengan lebih cepat dan besar (Isroi, 2008). Unsur hara $\mathrm{N}$ bermanfaat dalam menunjang pertumbuhan vegetatif tanaman, pertumbuhan tunas, perkembangan batang dan daun.

Mikroorganisme tanah lain yang berperan di dalam penyediaan unsur hara tanaman adalah mikroorganisme pelarut fosfat (P). Kandungan $\mathrm{P}$ dalam tanah umumnya tinggi terutama pada tanah-tanah pertanian yang terbiasa di beri pupuk anorganik P. Namun, hara $\mathrm{P}$ ini sedikit/ tidak tersedia bagi tanaman, karena terikat pada mineral liat tanah yang sukar larut. Untuk melarutkan unsur $\mathrm{P}$ diperlukan mikroorganisme pelarut $P$. mikroorganisme ini akan melepaskan ikatan $\mathrm{P}$ dari mineral liat tanah dan menyediakannya bagi tanaman. Banyak sekali mikroorganisme yang mampu melarutkan $\mathrm{P}$, antara lain: Aspergillus sp, Penicillium sp, Zerowilia lipolitika, Pseudomonas sp, Bacillus megatherium var. Phosphaticum. (Isroi, 2008). Unsur hara P dibutuhkan pada tanaman pada tahap awal bibit, pembentukan bunga, biji dan buah.

\section{KESIMPULAN}

Berdasarkan hasil yang diperoleh, maka dapat disimpulkan bahwa kompos dengan perombak Katalek merupakan kompos dengan kualitas terbaik dibandingkan pada kompos dengan perombak Promi. Media tanam yang merupakan kombinasi kompos dan tanah baik yang menggunakan perombak Katalek dan Promi merupakan media tanam yang dapat menunjang pertumbuhan sawi hijau terutama pada taraf 2:1. Media terbaik untuk 
pertumbuhan sawi hijau ditunjukkan oleh media 2 bagian kompos dengan perombak Katalek dan 1 bagian tanah.

\section{UCAPAN TERIMAKASIH}

Artikel ini merupakan bagian luaran dari kegiatan In House Reasearch mengenai "Pengembangan Kompos di Kebun Raya Cibodas" yang di danai oleh BKT Kebun Raya Cibodas Tahun Anggaran 2015. Penulis menyampaikan terimakasih kepada Kepala BKT Kebun Raya Cibodas Bapak Agus Suhatman, M.P. atas dana dan kepercayaan yang telah diberikan dan kepada seluruh staf pegawai Unit Pengelola Kompos serta kepada tenaga lapangan Daseng Ahmad S. yang telah membantu dalam pelaksanaan kegiatan ini.

\section{DAFTAR PUSTAKA}

Cáceres R., N. Coromina, K. Malin’ska, O. Marfà. 2015. Evolution of process control parameters during extended cocompost of green waste and solid fraction of cattle slurry to obtain growing media. Bioresource Technology. 179: 398-406.

Gomez, K.A., A.A. Gomez. 1995. Prosedur Statistik untuk Penelitian Pertanian, Terjemahan: Endang Sjamsuddin dan Justika S. Baharsjah, UI Press, Jakarta.

Hapsoh, Gusmawartati, A.I. Amri, A. Diansyah. 2017. Respon pertumbuhan dan produksi tanaman cabai keriting (Capsicum annuum L.) terhadap aplikasi pupuk kompos dan pupuk anorganik di polibag. J. Hort. Indonesia. 8(3): 203-208.

Haryanto, E., T. Suhartini, E. Rahayu, H. Sunarjono. 2007. Sawi dan Selada, Edisi Revisi. Penebar Swadaya. Jakarta.
Isroi. 2008. Makalah online: Kompos. Balai Penelitian Bioteknologi Perkebunan Indonesia. Bogor. https://isroi.files. wordpress.com/2008/02/kompos.pdf. [30 April 2014]

Kebun Raya Cibodas. 2013. Laporan Tahunan Balai Konservasi Tumbuhan Kebun Raya Cibodas Tahun 2010. Balai Konservasi Tumbuhan Kebun Raya Cibodas-LIPI. Cibodas.

Kebun Raya Cibodas. 2014. Laporan Tahunan Balai Konservasi Tumbuhan Kebun Raya Cibodas Tahun 2013. Balai Konservasi Tumbuhan Kebun Raya Cibodas-LIPI. Cibodas.

Kurniawati, F., M. Ariyani. 2013. Pengaruh media tanam dan pemupukan NPK terhadap pertumbuhan bibit damar mata kucing (Shorea Javanica). Sains Tanah Jurnal Ilmu Tanah dan Agroklimatologi. 10(1): 9-18.

Novizan. 2007. Petunjuk Pemupukan yang Efektif. Aromedia. Jakarta.

Sastro, Y., Ikrarwati, Suwandi. 2012. Peran granulasi dan pengayaan terhadap peningkatan efektivitas kompos pada sawi, selada, kangkung, dan bayam. J. Hort. Indonesia. 3(1):10-16.

Sidabutar, R.M. 2009. Pengaruh pemberian pupuk organik terhadap produksi sawi (Brassica Juncea L.) dan beberapa sifat kimia tanah pada Andisol. [Skripsi]. Universitas Sumatera Utara. Medan. 53 hal.

Suprapto. 2010. Peranan teknologi dalam upaya meningkatkan potensi nilai ekonomi sampah dalam sistem pengelolaan sampah domestik terpadu di Indonesia. Jurnal Teknologi Lingkungan Trisakti. 5(4): 1-7. 